\title{
ESCRAVATURA, CONCUBINAGEM \\ E CASAMENTO EM MACAU: \\ SÉCULOS XVI-XVIII
}

\section{Leonor Diaz de Seabra*}

\author{
Maria de Deus Beites Manso**
}

$\mathrm{D}$

e maneira generalizada, a presença social portuguesa no chamado

"Estado da Índia", da África Oriental a Timor, não agrupava mulheres de proveniências europeias, à exceção de algumas escravas e órfãs, quase sem representação no tecido social macaense. $\mathrm{O}$ Reino proibia o embarque de mulheres europeias para o Oriente, a não ser em casos muito especiais. ${ }^{1}$

Nessas circunstâncias históricas, não é fácil entender como, entre os séculos XVI e XIX, se foram agregando crianças, jovens e mulheres para alicerçar o processo de parentesco, famílias e unidades domésticas "portuguesas" e "luso-asiáticas" em Macau. ${ }^{2}$ Hoje, o desenvolvimento

* Professora da Universidade de Macau.1dseabra@gmail.com

** Professora da Universidade de Macau. mdmanso@netcabo.pt

1 Ana Maria Amaro, Filhos da terra, Macau: Instituto Cultural, 1988, p. 7. Ler: Clara Sarmento (ed.), Women in the Portuguese Colonial Empire: the Theatre of Shadows, Cambridge: Cambridge Scholars Publishing, 2008.

2 Leonor Diaz de Seabra, "Traços da presença feminina em Macau", Campus Social, n. 3-4, (2006), pp. 197-208. Sobre o assunto lembramos, igualmente, o estudo de Ivo Carneiro de Sousa, "Cativas e bichas, meninas e moças: a subalternidade social feminina e a formação do mercado matrimonial de Macau (1590-1725)”, Campus Social, n. 3-4 (2006), pp. 151-72. O autor baseou-se na documentação publicada por Leonor Seabra ("A Misericórdia de Macau (séculos XVI-XIX): irmandade, poder e caridade na Idade do Comércio", tese de Doutorado apresentada na Universidade do Porto, em 2007, e publicada pela Universidade de Macau, em 2011), destacando a formação de parentesco, famílias e unidades domésticas "portuguesas" e "luso-asiáticas" em Macau, com realce para o uso de alguns conceitos epocais. Recentemente, foi publicado um estudo que retoma 
de alguns estudos já mostra a formação de um sistema parental de predomínio social e cultural português, mas trata-se de um procedimento heterogéneo de longa duração, concertando desiguais organizações formativas, sendo uma das mais importantes a sistematização de um mercado nupcial baseado na mobilização da subalternidade social feminina que circulava no território. ${ }^{3}$

De acordo com as fontes históricas, ${ }^{4}$ nos primeiros tempos do estabelecimento dos portugueses em Macau, os homens tinham ali, na sua maioria, residência temporária. Inicialmente, faziam comércio em Macau, tal como nas ilhas de Shangchuan (Sanchoão) e Langbai'ao (Lampacau), erigiam unicamente casas provisórias de palha para a troca de mercadorias e prosseguiam ao mesmo tempo os diversos pontos de comércio em outras ilhas, o que se devia particularmente ao reconhecimento implícito e à permissão e proveitos económicos e pessoais dos mandarins locais, tanto distritais como provinciais. As ótimas condições geográficas de Macau e sua colocação como um porto aberto oficialmente para o comércio aliciavam aí cada vez mais comerciantes estrangeiros. ${ }^{5}$ Assim, de incipiente porto de pesca e de refúgio de juncos de comércio e de parco aglomerado de casas de madeira e tendas, Macau, a partir de 1557, assumiu um valor mercantil, dilatado pela colina chamada do Patane. ${ }^{6}$

No que respeita à demografia, em Macau, até à chegada dos portugueses, não se dispõe de muita informação. Os primeiros moradores de Macau, ao que se sabe, não se misturavam com a população chinesa. ${ }^{7}$

parcialmente a análise da mulher macaense: Elsa Penalva, Mulheres em Macau: donas honradas, mulheres livres e escravas, séculos XVI e XVII, Lisboa: Centro de História de Além-Mar, 2011. Seabra, "Traços da presença feminina", pp. 197-208.

4 Jordão de Freitas, Macau, materiais para a sua história no século XVI. Macau: ICM, 1988, pp. 15-8. Veja-se, também, Jin Guo Ping, "Combates a piratas e a fixação portuguesa em Macau", Revista Militar, n. 2364 (1999), pp. 199-228.

5 Wu Zhiliang, Segredos da sobrevivência: história política de Macau, Macau: Associação de Adultos de Macau, 1999, p. 45. Aconselhamos a leitura das páginas subsequentes que nos relatam as relações e negociações entre portugueses e chineses até à autorização de residência dos primeiros em Macau.

6 Jorge Manuel dos Santos Alves, Um porto entre dois impérios: estudos sobre Macau e as relações luso-chinesas, Macau, Instituto Português do Oriente, 1999, p. 67.

7 De uma maneira geral, por todo o Império Português do Oriente, sempre surgiram grandes obstáculos ao casamento entre os portugueses (outros europeus) e as mulheres locais. Quase sempre se relacionavam com grupos marginais à sociedade: prostitutas, órfãs, viúvas. Ver: Maria de Deus Manso, "A mulher 'outra' no espaço ultramarino português: o caso da Índia portuguesa", Textos de História, v. 11, n. 1-2 (2003), pp. 173-86; Timothy Coates, Degredados e órfãs: colonização dirigida pela coroa no Império português, 1550-1755, Lisboa: CNPCDP, 1998. 
Algumas fontes para depois de $1564^{8}$ estimam que a cidade era habitada por 600 portugueses, a que se somavam os seus escravos e criados. ${ }^{9}$ Esse número poderia ser superior, e haveria 1.500 habitantes dos quais 800 seriam europeus e luso-asiáticos, japoneses, chineses, siameses, malaios ou indianos..$^{10}$ Macau tornou-se a base das operações comerciais, e muitos dos comerciantes já partilhavam a vida com mulheres estrangeiras ou luso-asiáticas (japonesas, malaias, indianas, entre outras), sendo muitas delas escravas. Algumas negras africanas e numerosas escravas timorenses foram importadas mais tarde, contribuindo para a mistura racial. ${ }^{11}$ Em 1637, contudo, numa descrição da cidade de Macau, Peter Mundy refere que: "Os Portugueses casavam-se com mulheres chinesas e, gradualmente, a Cidade foi sendo assim povoada" (tradução das autoras). ${ }^{12}$

A dificuldade de aceder às mulheres chinesas e a escassez de mulheres europeias levaram a que muitos soldados, comerciantes, agentes políticos entre outros, ainda nas décadas finais no século XVI, se ligassem a grupos femininos subalternos asiáticos utilizando-se do rapto, da compra, da negociação e do resgate escravista. Desde a década de $1590,{ }^{13}$ diversas mulheres conseguidas e resgatadas em distintos lugares dos mares do Sul da China e do Sudeste Asiático, crianças e jovens chinesas continentais eram compradas ou raptadas em ações comerciais e marítimas, casando-se muitas delas com portugueses ou fiando suas serviçais,

8 Manuel Teixeira, SJ, a Leonel de Lima, SJ, BAC, Cartas do Japão, v. 3, fólio 103 e 103verso. (Cantão, 1-XI-1564).

9 Francisco Peres, SJ a Luís Gonçalves, SJ, Cartas do Japão, v. 3 (Carta de 3-XI-1564), in Boletim Eclesiástico da Diocese de Macau, n. 62, p. 770.

10 Alves, Um porto entre dois impérios, pp. 66-7. Veja-se, também, Manuel Teixeira, Macau no século XVI, Macau: Direcção dos Serviços de Educação e Cultura, 1981.

11 Charles R. Boxer, O Senado da Câmara de Macau, Macau: Leal Senado de Macau, 1997, p. 48. Cf. "Papéis de D. Francisco de Mascarenhas", Mss. da Biblioteca Pública e Arquivo Distrital de Évora, Cod. CXVI/2-5, fls. 226-32.

12 Charles R. Boxer (ed.), Seventh Century Macau in Contemporary Documents and Illustrations, Hong Kong: Kuala Lumpur; Singapore: Heinemann, 1984, p. 74. Alguns viajantes estrangeiros que chegaram a Macau entre os séculos XVI e XIX, e, ainda, as cartas dos missionários que se fixaram naquela cidade e dali partiam para as Missões do Oriente fazem referências às mulheres de Macau, que teremos de classificar como mulheres anónimas, que teriam acompanhado os portugueses, quando se estabeleceram em Macau. Ana Maria Amaro, "A mulher de Macau segundo os relatos dos viajantes", Revista de Cultura, n. 15 (1991), p. 119.

13 Arquivo Histórico de Macau (AHM): Núcleo da Santa Casa da Misericórdia (SCM) 15, fl. 4 (doravante citado por AHM/SCM/). Cf. Bento da França, Macau e os seus habitantes, relações com Timor, Lisboa: Imprensa Nacional, 1897. 
ou entravam num mercado sexual que, em larga medida, se encontra por investigar. Nos finais do século XVI, acentuou-se a prática do resgate e da compra de crianças e jovens chinesas, anuídas pelos poderes locais, recrutadas tanto entre as camadas mais pobres da população como entre as situações de orfandade da terra. Essa situação suscitou tantos medos e escândalos como foram criticados pela Igreja e pelas ordens religiosas missionárias, sobretudo pela enorme extensão do comércio da escravatura feminina impulsionado a partir do porto de Macau. ${ }^{14}$

No século XVI, o Reino interviera na repressão do comércio de escravos, no Oriente, porque, desde os mercados dos países árabes ao famoso mercado de Goa, os portugueses podiam comprar escravas provenientes das mais diversas partes da África e da Ásia, o que incrementou esse comércio de tal forma que, desde 1520, foi proibido por D. Manuel "que se levassem para a Europa escravos de qualquer casta", proibição reiterada em 1571, por D. Sebastião. Em 1595, na sequência de queixas das autoridades chinesas contra os portugueses que compravam raparigas daquela etnia para suas criadas e as exportavam como escravas, foram estabelecidas sanções pelo vice-rei da Índia, Matias de Albuquerque. ${ }^{15}$

Também durante o século XVII, foram feitas várias proibições sobre a escravatura de chineses. ${ }^{16}$ Aos residentes de Macau, naquela época, quase todos ainda ricos e poderosos ${ }^{17}$ pouco afectavam as leis do Reino, habituados como estavam a ser praticamente autogovernados, distantes da jurisdição de Goa e tendo, à frente do Senado, um grupo de mercadores que eram os mais ricos da cidade. ${ }^{18}$ A par das condenações eclesiásticas e da pressão das autoridades chinesas, continuavam a suceder-se as proibições do Reino, embora sem grande efeito prático. ${ }^{19}$

\footnotetext{
14 Leonor Diaz de Seabra, A Misericórdia de Macau (séculos XVI a XIX), Macau: Universidade de Macau; Porto: Universidade do Porto, 2011, p. 134.

15 Charles R. Boxer, Fidalgos no Extremo Oriente (1550-1770), Macau: Fundação Oriente/Museu e Centro de Estudos Marítimos de Macau, 1990, p. 229. Ver, também, Amaro, Filhos da terra, pp. 9-10.

16 Boxer, Fidalgos, pp. 228-9.

17 Veja-se Boxer, Fidalgos.

18 Boxer, Fidalgos, p. 231. A documentação medieval caracteriza os homens-bons como os mais ricos, os mais notáveis, os mais respeitados chefes de família, as pessoas honradas por excelência dentro de cada concelho. Era este o consenso de Macau: burgueses ricos e os mais conceituados, que monopolizavam os cargos municipais, decidindo questões administrativas e económicas.

19 Amaro, Filhos da terra, p. 11. Ver, também, Manuel Teixeira, Os macaenses, Macau, Imprensa Nacional, 1965
} 
As mulheres que ergueram famílias, sexualidades, serviços domésticos e geriram as "casas" de Macau eram sistematicamente asiáticas, predominantemente chinesas de baixa condição social, compradas, negociadas e raptadas com a colaboração das autoridades locais — as muitsai, como viriam mais tarde a ser conhecidas - , e representavam o sector mais frágil da população de Macau. Maioritariamente escravas, por isso despidas de quaisquer direitos, conseguiam por vezes a alforria pelo casamento ou pelo serviço, mas entravam também rapidamente em situações de subalternidade e marginalidade profundas. A falência de um mercador, um naufrágio, uma crise de abastecimento ou uma epidemia ecoavam mais duramente entre esta população atirada para as margens e inferioridade sociais da cidade. No entanto, apesar de sua fragilidade, esses grupos femininos eram absolutamente cruciais na estruturação de um comércio matrimonial que, gerando formas particularizadas de "oferta" e "demanda" de mulheres, se tornou vital na estruturação de parentescos euro-asiáticos e na reprodução de famílias mercantis. A Misericórdia de Macau acudia a estes dois movimentos: protegendo e apoiando a subalternidade social feminina do território, a irmandade soube também, pelo dote e pela esmola, mobilizar parte da população subalterna feminina para ser vazada nos casamentos que "salvaram" a sociedade de Macau. ${ }^{20}$

Como o infanticídio feminino era uma prática corrente na China, muitos chineses, pressionados pela miséria, em vez de matarem as suas filhas, vendiam-nas aos portugueses. ${ }^{21}$ Outros roubavam-nas ou compravam-nas aos seus conterrâneos para as revenderem em Macau. $\mathrm{O}$ comércio de crianças roubadas ou revendidas parece ter sido o meio mais usado para aquisição de muitsai, porque os chineses, na sua maioria, temiam represálias dos seus antepassados falecidos, no caso de os seus descendentes mudarem de religião, adoptando a dos bárbaros, uma vez que as crianças lhes fossem vendidas directamente. Desde o século XVI, praticava-se esse comércio em que se auferiam grandes lucros. ${ }^{22}$

20 O chamado "mercado nupcial" da cidade de Macau. Cf. Seabra, A Misericórdia.

21 A prática de vender tais raparigas aos habitantes de Macau começou muito cedo e continuou por mais de dois séculos, apesar das constantes proibições, tanto da parte das autoridades portuguesas como chinesas.

22 Luís Gonzaga Gomes, Monografia de Macau, por Tcheong-U-Lam e Ian-Kuong-Iâm, Macau: Imprensa Nacional, 1950, pp. 120-4. 
As escravas chinesas tinham sido, geralmente, raptadas quando crianças, por traficantes locais ou vendidas pelos próprios pais, podendo ser libertadas por alguém que as quisesse levar para suas casas como concubinas, ${ }^{23}$ prática, aliás, corrente na China, onde os chineses recorriam aos préstimos de cortesãs — as pei-pá-tchâiis ${ }^{24}$ — que tinham de se apurar no cultivo da música, pintura e literatura, tornando-se, assim, uma companhia agradável para os homens, nos seus serões..$^{25}$

Em meados do século XVII, com a quebra do comércio do Japão e a consequente decadência de Macau (1639), muitos homens portugueses deixaram a cidade e muitos deles abandonaram as suas famílias, deixando-as sem recursos económicos. ${ }^{26} \mathrm{Na}$ mesma época, começaram a afluir a Macau degredados e aventureiros - gente sem escrúpulos fugidos de Goa. É, pois, de admitir-se que teria sido a miséria material, aliada à "mentalidade de harém", que os portugueses mantinham nas cidades do Oriente onde viviam, o principal motivo que levou, então, muitas mulheres, principalmente criações $^{27}$ e escravas forras, ${ }^{28}$ à vida dissoluta que todos os viajantes do século XVIII lhes apontam. ${ }^{29}$

Assim, Frei José de Jesus Maria, no século XVIII, designava Macau como "cidade de mulheres", precisamente por haver grande número de mulheres entre a sua população. ${ }^{30}$ Ora, esse elevado número de mulheres na sociedade macaense devia-se, em parte, à existência de escravas chinesas e timorenses que, embora libertas a partir de 1758 , permaneceram na cidade, assim como aos frequentes naufrágios que deixavam muitas mulheres viúvas e crianças ou jovens órfãs de pai, conforme o comprova o pedido de autorização encaminhado pelo Senado da Câmara à Rainha de Portugal, em 1783, para a criação de um recolhi-

23 Luís Gonzaga Gomes, Curiosidades de Macau antiga, Macau: Instituto Cultural de Macau, 1996, p. 161

24 Isabel Nunes, "Bailarinas e cantadeiras: aspectos da prostituição em Macau”, Revista de Cultura, n. 15 (1991), pp. 95-117.

25 Gomes, Curiosidades, p. 160.

26 Charles Boxer, O grande navio de Amacau, Lisboa: Fundação Oriente/Centro de Estudos Marítimos de Macau, 1989.

27 Criações ou crioulas: mulheres escravas de diferentes etnias, que não chinesas.

28 Escravas forras: escravas libertas pelos amos.

29 Amaro, Filhos da terra, pp. 24-5.

30 Frei José de Jesus Maria, Ásia sínica e japónica, Macau: Instituto Cultural/Centro de Estudos Marítimos, 1988, v. 2, p. 221.

110 Afro-Ásia, 49 (2014), 105-133 
mento para "meninas órfãs e mulheres desamparadas", por muitas delas ficarem na "maior pobreza", em consequência dos "naufrágios frequentes". Além disso, devido ao regime de monções a que deviam obedecer as viagens, uma grande parte dos homens ausentava-se de Macau por longos períodos, acentuando-se ainda mais a predominância feminina, em certas épocas do ano. ${ }^{31}$

Essa predominância feminina, aliás, estava associada também às frequentes referências à prática da prostituição na cidade. Naquela altura, a prostituição era atribuída apenas às mulheres dos europeus pelas autoridades chinesas, mas há testemunhos que assinalam a existência de mulheres chinesas e timorenses dedicadas também a tal actividade. ${ }^{32}$ Uma outra característica da população feminina de Macau, naquela época, era, além da prática da mendicidade, a sua inatividade. Isso mesmo refere Frei José de Jesus Maria, admirando-se de as mulheres não se dedicarem "à fiação e ao bordado de algodão e seda ou a outras actividades afins", acrescentando que "nada faziam". 33

O excesso de mulheres era explicado, também, pelo facto de as mães chinesas de crianças do sexo feminino (normalmente, não desejadas) as abandonarem à nascença nas ruas ou entregando-as directamente ao Hospital das Enjeitadas. Uma vez que não havia espaço para as abrigar a todas, as enjeitadas eram entregues a mães adoptivas pobres, que recebiam um pequeno subsídio, pago mensalmente, para cuidarem das crianças até aos sete anos de idade. ${ }^{34}$ Depois desse período, a Misericórdia já não providenciava a manutenção das enjeitadas, nem se interessava mais pelo seu bem-estar. Como resultado, as amas (ou mães adoptivas) mandavam as crianças pedir esmola, a fim de ganhar o seu sustento, acabando, quase sempre, na prostituição. ${ }^{35}$

\footnotetext{
31 Maria de Jesus dos Mártires Lopes, "Mendicidade e 'maus costumes' em Macau e Goa, na segunda metade do século XVIII", in Artur Teodoro de Matos e Luis Filipe Thomaz (dirs.), As relações entre a Índia Portuguesa, a Ásia do Sueste e o Extremo Oriente - Actas do VI Seminário Internacional de História Indo-Portuguesa (Macau: Comissão Territorial de Macau para as Comemorações dos Descobrimentos Portugueses/Instituto Cultural de Macau/ Instituto Português do Oriente; Lisboa: Comissão Nacional para as Comemorações dos Descobrimentos Portugueses/Fundação Oriente, 1993), p. 74.

32 Lopes, "Mendicidade e "maus costumes", p. 73.

33 José de Jesus Maria, Ásia sínica, v. 2, p. 231.

Boxer, O Senado, p. 44

Boxer, O Senado, p. 45.
} 
Em 1750, dois mandarins, Tcheong Ü Lam e Ian Kuong Iam, enviados a Macau pelas autoridades chinesas, para averiguar qual o estado da cidade e dos seus habitantes, consideraram dois grupos de mulheres portuguesas "de acordo com a cor da pele": brancas (as senhoras) e negras (as escravas e/ou criadas). ${ }^{36}$ Seus relatos datam do século XVIII, quando a maioria das mulheres escravas eram timorenses, sendo já mais raras as negras, devido à diferença de preços. Naquela altura, a cidade estava empobrecida e vivia das viagens a Timor e a alguns portos da Índia, da Insulíndia e da Indochina, muito longe dos anos de riqueza que decaíram com o fim do século XVII.

A descrição dos viajantes chineses exalta o luxo e a extravagância dos portugueses, registando, ainda, que os homens não podiam manter em casa mais de uma esposa, porque a mulher se queixava ao bispo, e eles eram castigados, o que tem a ver com a proibição da bigamia, obviamente. Pelo contrário, os chineses ricos podiam manter, nas suas casas, várias esposas, sendo, no entanto, a primeira quem gozava das regalias de dona de casa e de mãe de todos os filhos. ${ }^{37}$ A moral confucionista mantinha, assim, o casamento monogâmico, mas exigia à mulher fidelidade absoluta ao marido. ${ }^{38}$ Daí, mostrarem-se os magistrados chineses chocados por “não ser proibido às mulheres portuguesas terem mais homens". É que, naquela altura, o estado de miséria moral e económica da cidade chegara a tal ponto de degradação, que os próprios chefes de família cediam as mulheres e as próprias filhas aos estrangeiros, para obterem algum lucro. ${ }^{39}$

Em 1758, um decreto de D. José I, aconselhado pelo Marquês de Pombal, proibia a escravatura das chinesas (muitsai), não tendo sido cumprido, tal como as proibições anteriores, ${ }^{40}$ situação que só se veio a

\footnotetext{
36 Tcehong-U-Lam e Ian-Kuong-Iâm, Ou-Mun Kei-Leok (Monografia de Macau), Macau: Mandarim, 1979, p. 208

37 Cecília Jorge e Beltrão Coelho, A fénix e o dragão: realismo e mito do casamento chinês, Macau: ICM-Editorial Pública, 1988, pp. 39-40.

38 Coelho, A fénix e o dragão, pp. 37-8.

39 Charles R. Boxer, Estudos para a história de Macau (séculos XVI a XVIII), tomo 1, Lisboa: Fundação Oriente, 1991, p. 179.

40 Boxer, Fidalgos, p. 231.

112 Afro-Ásia, 49 (2014), 105-133
} 

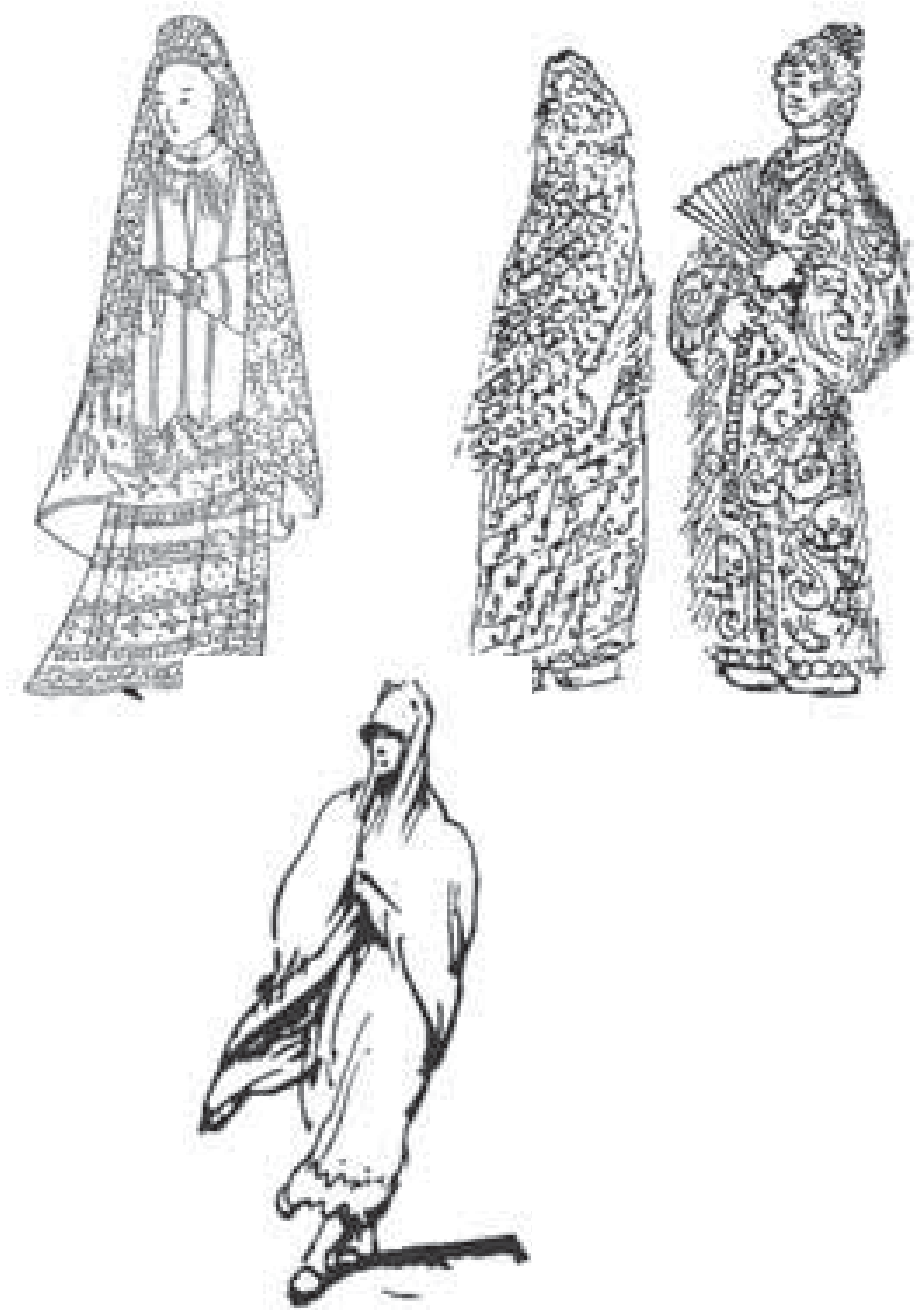

Mulheres de Macau (Peter Mundy - séc. XVII). / Mulher macaense com saraça ${ }^{41}$ (Tcehong-U-Lam e Ian-Kuong-Iâm, Ou-Mun Kei-Leok (Monografia de Macau), Macau: Tipografia Mandarim, 1979, p.149.)

Mulher macaense com saraça e bioco ${ }^{42}$ (Esboço-Chinnery).(Tcehong-U-

Lam e Ian-Kuong-Iâm, Ou-Mun Kei-Leok (Monografia de Macau), Macau: Tipografia Mandarim, 1979, p.149.)

${ }^{41}$ Saraça: de origem malaia (sarásah) ou do sânscrito (sârasa), inicialmente era um tecido de algodão estampado (batik) ou em seda - trazido da Índia e, mais tarde, de Manila — enrolado à cintura, para servir de saia, e outro, na cabeça, espécie de véu ou mantilha.

42 Bioco: espécie de véu ou mantilha rendada, usado na cabeça a cobrir o rosto. 


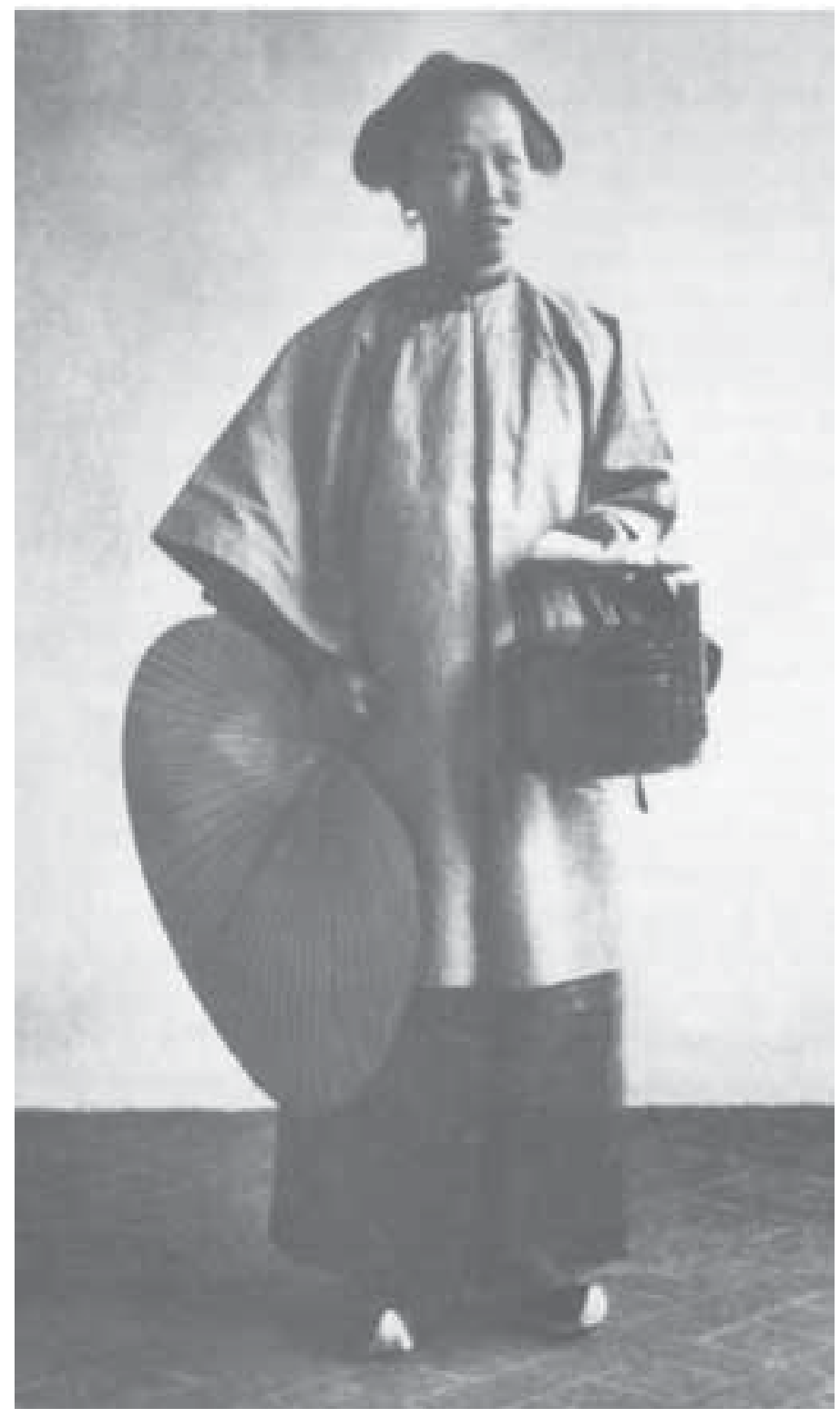

Muitsai (c. 1868) $)^{43}$

${ }_{43}$ Muitsai (c. 1868), in Kenneth Gaw, Superior Servants: the Legendary Cantonese Amahs of the Far East, Singapore: Oxford University Press, 1991, p. 15.

114 Afro-Ásia, 49 (2014), 105-133 
resolver definitivamente mais tarde, pela lei de 23 de fevereiro de 1869 , que levou à extinção da escravatura em todos os domínios portugueses.

\section{Nhons, nhonhona, nhim, aias e amas}

Segundo Ana Maria Amaro, os nhons e nhonhona eram os descendentes dos portugueses do Reino, sendo as nhim as senhoras casadas e, habitualmente, de estatuto socioeconómico desafogado. A documentação só refere nhons (naturais da terra), filhos e netos dos portugueses, mas não às suas filhas, que ficaram sempre integradas no grupo de mulheres casadas ou solteiras, se não no grupo das escravas, sem discriminação de etnia (século XVI-XIX). ${ }^{44}$

Havia, ainda, as aias, mulheres também lusodescendentes de classe social menos favorecida, que eram contratadas para damas de companhia das filhas das famílias mais ricas e que as acompanhavam quando elas se casavam, passando a fazer parte da sua nova família. Além das aias, cada criança de família macaense rica tinha a sua ama chinesa, que podia aleitá-la ou não, mas que era por ela responsável. As amas eram contratadas, e era-lhes pago um salário, além de lhes ser fornecida "cama e mesa", o que habitualmente constava dos contratos. Muitas delas ficavam incorporadas nas grandes famílias até morrerem, se o desejassem, sendo algumas catequizadas e baptizadas, mesmo já muito idosas (séculos XIX-XX). ${ }^{45}$

\section{Órfãs e viúvas}

Tanto os casamentos como a concubinagem com mulheres pertencentes a camadas baixas da sociedade chinesa causaram medos e escândalos e foram criticados pela Igreja e pelas ordens religiosas missionárias, o que motivou o estabelecimento de regras que organizassem a sociedade em que o elemento português estivesse maioritariamente representado. ${ }^{46}$

Em 1569, a Misericórdia de Macau passou a conduzir social e

\footnotetext{
44 Amaro, "A mulher de Macau", p. 119.

45 Ana Maria Amaro, "A mulher macaense, essa desconhecida", Revista de Cultura, n. 24 (1995), p. 9.

46 Seabra, A Misericórdia, pp. 135-68.
} 
"moralmente" o casamento, impondo-lhe dote, normas e, sobretudo, a formação católica das jovens e mulheres asiáticas pretendentes ao casamento ou ao serviço entre as "famílias da terra". ${ }^{47}$

Uma das categorias que mais convocava a generosidade testamentária dirigida à Santa Casa macaense encontra-se na noção geral de "órfãs", rapidamente se compreendendo que o seu principal destino social se jogava na possibilidade de obter os dotes indispensáveis para garantir a sua circulação no mercado nupcial do território. ${ }^{48}$

Algumas mulheres confiavam verbas significativas das suas testamentárias para apoiar o casamento de órfãs e viúvas, tanto dos seus próprios meios familiares, como oriundos da subalternidade que se entregava aos cuidados caritativos da Misericórdia. Essa produção testamentária feminina é especialmente importante, porque denuncia a apropriação de fortunas mercantis impressivas por mulheres residentes em Macau, maioritariamente de origens chinesas e asiáticas, enviuvando geralmente cedo e conseguindo acumular poder e prestígio sociais que, depois, começavam, por meio de documentação formal, a concretizar expressões tanto testamentais como jurídicas.

Neste panorama heterogéneo, existem ainda outros casos em que os legados testamentários optam não apenas por generalizar piedosos dotes em direcção a órfãs e viúvas, mas estipulam condições éticas importantes para a sua concretização. Se as condições morais remetem a categorias gerais da ética cristã que, como a "boa fama" e a "honestidade", se cruzavam com a "pobreza" e o "desamparo", mais relevante se mostra a hierarquização que distinguia a donzela - uma mulher solteira virgem - da viúva, o derradeiro segmento social em situação de subalternidade a consolar, dotar e (re)colocar no comércio matrimonial, operando como uma espécie de reserva demográfica e conubial.

\section{Cativas e bichas}

A maioria das órfãs e viúvas que receberam apoios gerais ou particulares

\footnotetext{
47 Seabra, A Misericórdia, pp. 135-68.

48 Seabra, A Misericórdia, p. 135.
}

116 Afro-Ásia, 49 (2014), 105-133 
(legados) era de origem chinesa e asiática, mas exibia condições sociais muitas vezes completamente opostas. ${ }^{49}$ É precisamente desta dispersão de posições estamentais e consideração sociossimbólica que se retoma a significação de alguns conceitos femininos. Tendo por base a leitura de testamentos, verificamos que a situação de escravatura feminina é geralmente categorizada a partir da noção de "cativa". Algumas cativas foram colocadas em casas de antigas escravas alforriadas que tinham conseguido dispor dos dotes dos seus senhores para casar e traçar as suas próprias unidades familiares. É o que se desvenda nas disposições testamentárias que, em 1610, Isabel Taveira dirigiu à vigilância da Misericórdia de Macau, caso em que a testadora obrigou a irmandade a executar a sua derradeira vontade de deixar durante quinze anos "em cativeiro" duas "cativas chinas" na casa de Paula Sira que, de origem chinesa, tinha sido também sua escrava antes de receber a alforria para se casar com um mercador português activo no território. ${ }^{50}$

A partir de 1631, as fontes testamentárias começam a associar estreitamente as categorias de cativas e bichas. ${ }^{51}$ Com efeito, seguindo as lições do testamento fechado a 24 de janeiro daquele ano por Luísa Pereira, recupera-se um documento dirigido à Misericórdia de Macau em que a testadora decidia a sorte de uma sua escrava chinesa nos precisos termos:

[...] a bicha por nome Antónia nascida em minha casa de idade de 19 anos pouco mais ou menos deixo forra e the deixo 100 pardaus de reales para seu casamento e assim mais o rosário de coral com seus extremos de ouro e cruz que no testamento se declara e dois caixões um grande e outro pequeno e a cama onde falecer, o qual dinheiro e o mais se dará para seu casamento.

Apesar dessa caridade, que convocava mesmo objectos de uso e

\footnotetext{
Seabra, A Misericórdia, p. 155.

Seabra, A Misericórdia, p. 146

51 A condição (proibida) de escravas levou à criação de uma nova categoria na estrutura familiar dos portugueses de Macau — a de criações ou crioulas, as quais não eram escravas, mas também não eram completamente livres. Usavam-se, ainda, as designações de nhins, nhons e nhonhonha, ou amas, aias, e bichas, como diferentes estatutos de mulheres macaenses euro-asiáticas e chinesas - e mesmo de outras etnias - que integravam as famílias locais. As criações eram as crianças compradas ou as filhas e os filhos ilegítimos (do chefe de família ou dos nhons, seus descendentes), mas tinham um estatuto que não era bem o da bicha, antiga escrava ou serviçal, não sendo também o de afilhada. Ler: Amaro, Filhos da terra.
} 
devoção pessoais, Luísa Pereira não deixou de recomendar que, caso a sua Antónia "não proceda bem", o dote deveria permanecer intacto nos cofres da Misericórdia macaense. Para proteger a vontade da importante testadora, o próprio provedor da irmandade providenciou para que se colocasse Antónia em casa de Francisco Monteiro Homem, na altura juiz dos órfãos. ${ }^{52}$ Num caso raro de depreciação, a irmandade diminuiu os ganhos do legado, em 1689, em 16 taéis, limitando apenas o volume de missas pela alma da doadora. ${ }^{53}$

Identificado até aqui como um termo referenciando a escravatura feminina infantil e juvenil de origem chinesa, o conceito epocal de bicha mostra-se mais amplo na documentação, abarcando outras situações de escravatura feminina asiática, na sociedade macaense seiscentista. Assim, no testamento encerrado em 1634 por Rui Vaz Pinto, comerciante estabelecido em Macau, começa por se responsabilizar a Santa Casa por "uma moça casta china por nome Grácia que está em casa de Bernardo Gracês, a qual deixo à minha afilhada para servir os anos que tem de serviço e no cabo lhe façam bem". Seguem-se disposições sobre "uma bicha casta bengala" que deveria servir trinta anos "a uma menina por nome Maria órfã para que a sirva que está em casa de Bernardo Garcês". Deixou à sua bicha Grácia "20 pardaus que se dêem a ganhos até que se case". A bicha foi, depois, entregue pela Misericórdia na casa de Luís Tomé, onde se acolhia também a órfã Maria. ${ }^{54}$

Noutros casos, encontramos testadores a encaminhar as suas escravas para afilhadas pobres, como ocorreu com Bárbara de Lemos que, a 27 de junho de 1632, deixava as suas casas a uma sua afilhada, filha de António Nunes, pedindo à Misericórdia que, por "ela ser pobre", empregasse os rendimentos para evitar que deitasse "fora a Maria Nunes por ser pobre enquanto for possível". Mas, como a escrava Maria morreu, a Santa Casa herdou as casas de Lemos e vendeu depois em proveito próprio. ${ }^{55} \mathrm{O}$ mesmo tipo de circulação social encontra-se nas disposições testamentárias dirigidas à Misericórdia de Macau por Miguel Correia da

\footnotetext{
$\mathrm{AHM} / \mathrm{SCM} / 302$, fls. $28 \mathrm{v}-29$.

$\mathrm{AHM} / \mathrm{SCM} / 302$, fl. 55.

AHM/SCM/302, fls. 32-32v.

55 AHM/SCM/302, fls. 31-31v.

118 Afro-Ásia, 49 (2014), 105-133
} 
Costa, a 15 de março de 1637. O testador decide deixar forra "uma menina que tem em sua casa Anica casta china", depositando na Santa Casa 200 "pardaus de reales" que "são para arriscar até ao seu casamento" e deixando-lhe ainda duas bichas, uma "Catarina casta bengala e Jacinta casta Macassar". ${ }^{56}$

Não se pense, porém, que esse tipo de disposições testamentárias se encontra estavelmente pautado apenas por exemplos de caridade, culminando na alforria e dotação matrimonial dessa escravatura feminina doméstica. Tropeça-se, por vezes, com testamentos em que a distribuição de devotas intenções derradeiras se emaranha com manifestos sinais de discriminação de algumas cativas, denotando esta espécie de "ajuste de contas" final das incoerências que se viviam no interior das famílias amplas, agregando à família biológica esta outra "família" de criados, servidores e escravos.

Em 1655, Maria de Torres resolve entregar à Santa Casa a importante quantia de 3.000 cruzados mais as suas casas, hortas e boticas, metade para "a confraria do Santíssimo Sacramento da minha freguesia" e a outra parte para dotar o casamento das suas "moças excepto o bicho José que não terá parte alguma nesta repartição". Infelizmente, as suas outras duas escravas chinesas haveriam de falecer antes de casarem, sendo o dinheiro do legado embolsado pela Misericórdia, que vendeu ainda em leilão os bens restantes. Numa informação com interesse para a história dos preços de Macau, as duas casas e hortas deixadas por Maria de Torres renderam, em 1681, a quantia de 626 taéis, enquanto as boticas se venderam por 96 pardaus. ${ }^{57} \mathrm{~A}$ provedoria $\mathrm{e}$ a Mesa da irmandade decidiram posteriormente que se empregassem esses recursos expressivos no apoio às "órfãs e viúvas da Santa Casa". ${ }^{58}$

No final do período em estudo, em 1725, parece terem-se alargado as condições e extensão do recrutamento dessa escravatura feminina. É o que sugere o testamento ditado no mesmo ano por Paula Correia, deixando à Misericórdia as suas casas e roupa para a manutenção das suas "duas criações e três moças": Micaela, 40 anos; Maria, de 26; "Joana, moça timora, 60"; "Esperança, timora, 70"; "Dorotea, timora, 50". Infelizmente, como informava o empenhado escrivão desse ano da irmandade, “em 1754

\footnotetext{
${ }_{56} \mathrm{AHM} / \mathrm{SCM} / 302$, fl. 36.

AHM $/ \mathrm{SCM} / 302$, fl. $52 \mathrm{v}$

$\mathrm{AHM} / \mathrm{SCM} / 277$, fl. 13
} 
estavam falecidas todas as criações e moças", pelo que os bens pródigos de Paula Correia verteram com os seus ganhos para os cofres da Santa Casa. ${ }^{59}$

Ao longo do século XVIII, em ligação com o exclusivo do sândalo, os comerciantes de Macau começam a carregar em Timor claras quantidades de escravos, com especial destaque para uma farta jovem escravatura feminina que começou a invadir as unidades domésticas privadas e mesmo instituições públicas e religiosas de Macau. Apesar dos números excessivamente redondos do testamento de Paula Correia - destacando mais "qualidades" do que "quantidades" - , as três escravas timorenses beneficiadas pelas suas últimas vontades parecem indiciar resgates feitos ainda no início do período setecentista, precisamente quando tratos escravistas consolidaram o interesse dos mercadores macaenses pelas viagens marítimas à ilha de Timor. No entanto, o aumento da população escrava de Macau acabaria por acrescentar também a colecção de investimentos na sua assistência que, correndo a par com a multiplicação de situações de funda subalternidade, suscitaram a especialização e o aparecimento de novas instituições sociais de acolhimento e caridade, como as casas de "expostos" e "enjeitados", os "recolhimentos" e "colégios".

\section{Amuis}

Sempre que a documentação procura discriminar a escravatura chinesa feminina, sobretudo comprada e cambiada em tenra idade na região do Delta do Rio das Pérolas, utiliza termos locais, a partir do cantonense, como é o caso de amui. É o que se testemunha, entre outros, em processo depositado no Leal Senado, em que a vereação camarária se reúne, em 1703, produzindo esta interessante deliberação:

Para acabar uma caria ${ }^{60}$ de uma Amui que nesta cidade ficou de Diogo de Melo com o china Mandarim de Hian-xan para que mais se não fale na dita Amui, dando sua chapa com toda a segurança; e para se evitar o que com a entrega dela pode suceder; convieram todos uniformemente que vindo os papéis correntes se vendesse a dita Amui com o pretexto de não sair para fora da terra pela quantia de 21 patacas. ${ }^{61}$

\footnotetext{
AHM/SCM/ 304, fl. 34.

60 Caria: questão, desavença.

${ }^{61}$ Arquivos de Macau, 3. " série, II vol., n. 1, julho de 1964, pp. 44-5: "Termo feito em junta de Homens bons sobre se não venderem Amuis ou atais para fora da Terra (1703, Julho, 14)".
} 
A circulação das jovens mulheres compradas em Guandong era muito frequente em Macau, mas, como esclarece temerosamente a vereação do Leal Senado, complicada, sempre que a compra e o resgate gerasse problemas entre as autoridades imperiais locais. Por isso, este processo concreto veio a demorar-se. As contradições prolongaram-se e, em julho daquele ano, a vereação reuniu-se de urgência para proibir a venda de atais e amuis "para evitar carias com os Chinas", decidindo não permitir que se vendesse "a forasteiro algum" nem que se mandasse "para fora da terra pelo grande prejuízo que disso seguia". ${ }^{62}$

A própria vereação dos "senadores" sabia perfeitamente que, sem mulheres compradas na China, muitas com apenas meses de vida, dificilmente se reproduziria a sociedade macaense: faltaria "oferta" no mercado matrimonial, escasseariam os serviços domésticos e limitar-se-iam outras situações mais "mundanas".

\section{Meninas e moças}

As expressões genéricas tipológicas que temos vindo a utilizar param. A terminologia é frequentemente tão instável como imprecisa, até porque frequenta maioritariamente mulheres em escravatura e, por isso, despidas de quaisquer direitos, constituindo formal e normativamente uma espécie de "grupo sem direito". Nesse campo, é precisamente a circulação dessas escravas entre serviço e alforria, entre doação e transmissão caridosa que vai precisamente concebendo algumas franjas de direitos entre o consuetudinário e a herança. Seja como for, a mutabilidade da nomenclatura social da documentação não pode deixar de sublinhar a preferência por dois termos gerais - menina e moça —, que são os qualificativos mais abundantes na documentação e tendem mesmo a acompanhar, preceder ou adjectivar algumas das situações de subalternidade de órfãs, viúvas, bichas e cativas. É possível que, ainda nos finais do século XVI, as noções de menina e moça auxiliassem a perspectivar, pela formalização de uma escrita jurídica, modelos de subalternidade social feminina, de

\footnotetext{
${ }^{62}$ Arquivos de Macau, 3. a série, II vol., n. 1, julho de 1964, pp. 44-5: "Termo feito em junta de Homens bons sobre se não venderem Amuis ou atais para fora da Terra (1703, Julho, 14)".
} 
desigual representação etária, social e simbólica, que a documentação testamentária tentava tratar de um ponto de vista substancialmente piedoso e caritativo. Apesar de se acharem os dois termos num mesmo documento, ${ }^{63}$ uma pesquisa comparativa das fontes disponíveis parece sugerir algumas diferenças na sua utilização: menina aplica-se geralmente a uma escrava ou dependente feminina infantil e adolescente, ${ }^{64}$ enquanto $m o c ̧ a$ se associa a escravas e dependentes femininas jovens e adultas em idade conjugal. ${ }^{65}$ Não se consegue apurar a dimensão etária quantitativa precisa da distinção - recorde-se, atrás, essa "Joana, moça timora" ${ }^{66}$ de 60 redondos anos -, mas a ocorrência simultânea dos dois termos num único testamento autoriza a sublinhar esta especialização. ${ }^{67}$ Meninas e moças têm em comum uma predominante subalternidade social, sendo esmagadoramente "escravas" ou "libertas" de origens asiáticas e "mestiças", circulando no interior de unidades domésticas de Macau, sob o acolhimento maioritário de um protector/senhor masculino que, mercador ou com fortes ligações aos negócios enérgicos pelo enclave, movimenta os seus rendimentos para lhes mover uma educação cristã, abrigo em sua casa ou de pessoa de sua confiança, alimentação e vestuário, em troca de favores que iam das comunicações sexuais ao trabalho doméstico. ${ }^{68}$

Estendendo a sociologia e o estado dessas protecções masculinas, noutros documentos testamentários encontrámos sacerdotes seculares, instalados em Macau, a dotar o casamento de algumas meninas da sua preferência. ${ }^{69}$ Registem-se neles, como nos tipos testamentários anteriores, a generalizada preferência pelo diminutivo antroponímico dessas meninas e acrescente-se, ainda, a opção complementar em apoiar alternativamente um futuro matrimónio ou a entrada na vida religiosa que, nos casos femininos, se dirige sempre para as Clarissas de Macau. Esta alternativa opcional tem ainda a vantagem de explicitar a faixa etária pueril dessas mulheres, ainda suficientemente afastada de um acesso ao

\footnotetext{
AHM/SCM/302 - "Testamentos".

AHM/SCM/302 - "Testamentos",

$6 \mathrm{AHM} / \mathrm{SCM} / 302$ - "Testamentos".

AHM/SCM/302, fl.14.

AHM/SCM/302, fl. 44

AHM/SCM/302, fl. 14; AHM/SCM/302, fl. 4v

AHM/SCM/302, fls. 9-9v; AHM/SCM/302, fl. 55v.
}

122 Afro-Ásia, 49 (2014), 105-133 
noviciado na segunda ordem dos menores que, nos casos mais precoces, se concretizava entre os dez e catorze anos, contra dotes generosos e estáveis. $^{70}$

Em contraste etário e mesmo simbólico, sempre que se recupera a noção de moça ou que se cruza, num mesmo documento, com o termo menina, ganha-se, com algum aproximado rigor, distinções na categorização e circulação da subalternidade social feminina destinada a movimentar-se no mercado matrimonial de Macau. ${ }^{71}$ Os conceitos de menina e moça distribuem distinções etárias e mesmo sociossimbólicas, mas discriminam mal as situações estamentais de inferioridade social feminina: não se associam excessivamente com as noções de cativas e bichas, adjetivando também pobremente as situações de orfandade. Tendem, por isso, a mover-se como grupos com alguma autonomia nocional em que se coligam dimensões etárias, familiares e sociais múltiplas, obrigando frequentemente as fontes testamentárias a utilizar outras categorias, mobilizando já valores morais, já também formas significativas de alianças clientelares em que parece ter assentado socialmente, de forma significativa, a sobrevivência das famílias extensas de mercadores portugueses instalados em Macau. Multiplicando unidades domésticas que abrigavam muitas crianças, jovens e mulheres em situação de subalternidade e sujeição, essas famílias foram criando um efectivo modo de rede clientelar em que alguns dos seus "nós" se enleavam justamente graças à circulação e às alianças, facilitadas pelo poder de colocação, no mercado matrimonial de Macau, dessas muitas situações de subalternidade social feminina. Trata-se de uma espécie de "sistema da dádiva", em que a circulação, pela paisagem social, das mulheres em situação subalterna operava como um "presente" essencial na movimentação dos capitais que, sob a forma de dotes, garantiam alianças de famílias e interesses, a partir de um intercâmbio matrimonial.

\footnotetext{
70 Manuel Teixeira, Macau e a sua diocese, v. 3: As ordens e congregações religiosas em Macau. Macau: Tipografia Soi Sang (1956-1961), pp. 483-510.

71 Sobre o assunto, veja-se Seabra, A Misericórdia.
} 


\section{Afilhadas e donzelas}

Sempre que a produção testamentária da Santa Casa encontra personagens poderosas, coligando poder senhorial e económico, alargam, mas também se especializam, os tipos de inferioridade feminina protegidos. ${ }^{72}$ Em 1664, o padre Manuel Pereira, por exemplo, dono de vários escravos, depositava ao cuidado da Misericórdia o seu testamento reunindo um impressionante rol de "protegidas" e "afilhadas". ${ }^{73}$ Sublinhe-se a grande importância social da circulação das "afilhadas", no interior das redes de ascendência e de clientela, com que se procurava organizar e hierarquizar as famílias de mercadores portugueses estabelecidos em Macau. Ao mesmo tempo, verifica-se a importância do controlo de jovens em subalternidade social e a sua distribuição, enquanto verdadeiro "mercado nupcial", empregando modalidades tanto de dotação, como de acesso ao casamento preferencialmente com "portugueses".

Ao estruturar esta circulação que deveria terminar no casamento, alguns testamentos singulares introduziam, nos processos de protecção da inferioridade social feminina, outras categorias dispondo outras identificações culturais e familiares, abrangendo o "reconhecimento" de filhas naturais. Assim, no testamento que se concluiu a 28 de janeiro de 1627 , o mercador André de Figueiredo resolveu deixar todos os seus bens a "uma filha natural por nome Domingas de Figueiredo, que está em Goa em casa de Francisco Leitão de Andrade", obrigando a Misericórdia de Macau a confirmar, junto da irmandade goesa, a observância de suas últimas vontades. ${ }^{74}$

Se o reconhecimento de descendências mais afastadas parece magnânimo às portas da morte, também se encontram testadores que decidem dotar a sua linhagem natural feminina de Macau, num gesto de maior coragem social. Falecido a 30 de setembro de 1641, Belchior de Barros Pereira dirigiu à Misericórdia o seu testamento, em 1637, explicando que

[...] novecentos e cinquenta taéis e seis caixas de saipi declarou dever a

\footnotetext{
72 Biblioteca da Ajuda 49/V/5: "Principião as notas do ano de 1607. Testamento de Maria Gaya", fls. 75-7.

73 AHM/SCM/302, fls. 77v-78v.

${ }^{74} \mathrm{AHM} / \mathrm{SCM} / 302$, fl. $24 \mathrm{v}$.

124 Afro-Ásia, 49 (2014), 105-133
} 
sua filha natural, por nome Maria de Barros, que lhos deixou meu cunhado Manuel da Cruz Ferraz e eu os cobrei da Santa Casa da Misericórdia, ficando por fiador desta prata João Vieira que, para segurança dela, depositado está em seu poder uma boceta com jóias, a saber, uma gargantilha de diamantes, uma fita de diamantes e seus aljofres, um pensamento de diamantes bons, um plumeiro de diamantes, um prego de diamantes, uma cruz de diamantes, oito colheres e oito garfos; assim mais fora da buceta está na mão do dito João Vieira dois púcaros e dois pratos de prata, obra de Japão, um jarro e um prato de água das mãos obra de Manila, e um gumil de prata — este gumil se João Vieira o quiser se separa e abaterá na dívida que eu the estou devendo -; declaro que esta prata que estou devendo a minha filha Maria de Barros tinha de ganhos alguma cousa, ainda que pouca, por onde lhe deixo um púcaro e um prato, grande obra de Japão de minha lembrança. ${ }^{75}$

Esse documento beneficiando generosamente uma "filha natural" permite sublinhar a importância dos capitais em alfaias que circulavam como dotes matrimoniais, no caso a partir de ricas obras de ourivesaria, realizadas no Japão e em Manila.

A noção de donzela deverá associar-se à recorrente presença do conceito de castidade, que fomos encontrando em vários documentos testamentários, procurando colocar, no mercado nupcial de Macau, jovens, não apenas protegidas por dotes importantes, mas também social e moralmente prestigiadas pela sua virgindade, condição indispensável para o acesso a um matrimónio cristão. ${ }^{76}$

\section{Recolhidas e enjeitadas}

Ao longo do século XVIII, em comunicação com o monopólio do sândalo, os comerciantes de Macau começaram a carregar em Timor elevadas quantidades de escravos, com especial destaque para uma abundante jovem escravatura feminina que começou a apoderar-se de unidades domésticas privadas e mesmo instituições públicas e religiosas de Macau. No entanto, como dito acima, a extensão da população escrava de

\footnotetext{
AHM/SCM/302, fls. 40-40v.

76 AHM/SCM/303, fl. 8; AHM/SCM/302, fls.74v-75.
} 
Macau acabaria por ampliar também a colecção de investimentos na sua assistência que, constando a par com a proliferação de situações de funda subalternidade, suscitaram a diferenciação e o aparecimento de novas instituições sociais de acolhimento e caridade, como as casas de "expostos" e "enjeitados", os "recolhimentos" e "colégios".

Muito menos regularmente, algumas das filhas segundas da grande burguesia comercial de Macau recebiam dotes para entrar na clausura do mosteiro de Santa Clara de Macau. As Clarissas tinham entrado no território em 1633, vindas de Manila, mas desenvolveram uma casa religiosa contemplativa e enclausurada, seguindo a dura regra coletina da segunda ordem franciscana, não conseguindo organizar uma comunidade que, em média, reunisse mais de trinta religiosas, pelo que não conseguiam atrair e acomodar muitas das órfãs de famílias suficientemente ricas para cumprir os dotes necessários à profissão das suas filhas. As Clarissas de Macau foram mesmo vivendo graças a um subsídio anual do Leal Senado, de $0,5 \%$ sobre as mercadorias entradas no enclave em embarcações portuguesas, mas a esmola nem sempre foi paga, e as religiosas haveriam frequentemente de ser encaradas, pelos senadores, como uma incomodidade que pouco tinha a ver com as relações sociais especializadas pela sociedade local cristã. ${ }^{77}$ Tratava-se de uma experiência religiosa que não alimentava, naturalmente, a reprodução dos casamentos cristãos das famílias "portuguesas" e, muito menos, respondia à grande movimentação de mulheres em situação de subalternidade social, em que continuadamente se arrolava grande número de órfãs e viúvas.

Só muito tardiamente, em 1726, tentou a Misericórdia criar uma solução institucional permanente para controlar essa pobreza feminina que, até aqueles horizontes cronológicos, era apenas apoiada com esmo-

\footnotetext{
77 Acerca da fixação das Clarissas em Macau e as suas relações com o Leal Senado, as fontes mais representativas afiguram-se ser os seguintes registos: AHM/LS, 531, "Termos dos Conselhos Gerais do Leal Senado (1630-1685)", s.p. (1633, Dezembro, 16); AHM/LS, 531, “Termos dos Conselhos Gerais do Leal Senado" (1630-1685)", s.p. (1633, Dezembro, 24); AHM/LS, 531, "Termos dos Conselhos Gerais do Leal Senado (1630-1685)", s.p. (1637, Setembro, 2); AHM/ LS, 530, "Termos dos Conselhos Gerais do Leal Senado (1685-1709)", fl. 13v.; Arquivos de Macau, 3. ${ }^{\text {a }}$ série, v. 1, n. 2, Março 1964, pp. 87-8: "Termo do acordão que se tomou em Junta de Homens bons, sobre se houver de dar os por centos às Madres de Santa Clara com as condições que o povo atraz tem assentado (1692, Outubro, 13)". Veja-se, também, Teixeira, Macau e a sua diocese, v. 3, pp. 483-510.
} 
las circunstanciais muitas vezes distribuídas em arroz na Casa e igreja da irmandade..$^{78}$ No mesmo ano, quando a Santa Casa era dirigida pelo provedor António Carneiro de Alcáçova, governador e capitão-geral de Macau, decidiu a Mesa começar a "fazer o novo mosteiro de recolhimento das órfãs e viúvas pobres" ${ }^{79}$ Dois anos mais tarde, em 1728, em reunião de 10 de março, a Mesa deliberou também contratar um médico a "petição da regente das recolhidas desta Santa Casa", optando por nomear o Dr. Francisco Jacob Vandelms, por duas patacas por mês de salário. O recolhimento tinha sido aberto para trinta órfãs e viúvas "das mais pobres" da cidade, seleccionadas com o estreito apoio e controlo dos párocos de Macau. A instituição era dirigida por uma regente e duas serviçais, permitindo o acolhimento permanente a esse número de "pobres mulheres", que recebiam mensalmente uma esmola de um tael de prata e cerca de dois quilos de arroz. ${ }^{80}$

No entanto, oito anos decorridos sobre a abertura do recolhimento que a documentação da irmandade prefere apresentar como "o mosteiro das recolhidas", em 1734, a situação da casa tornou-se mais do que difícil. Em reunião de 24 de outubro do mesmo ano, provedores e mesários verificaram criticamente "que não havia livro de entrada das recolhidas e que também não se podia conservar o recolhimento, porquanto esta Santa Casa não tinha nada do seu património, nem o dito recolhimento nada decerto de rendimento". Mais ainda, informa a reunião que o rendimento dos defuntos não se podia estender ao recolhimento porque era utilizado em dotações matrimoniais, o $1 \%$ devido pelo Senado não chegava para cobrir as despesas, e a esmola prometida pela Companhia de Jesus não tinha sido paga. Resultado imediato, "por ordem da Mesa se tinha tirado uma lista das recolhidas sem esta tão precisa circunstância e que se tinha feito reforma avisando-se algumas para saírem por não terem as qualidades que se requerem". ${ }^{81} \mathrm{Na}$ mesma reunião, a Mesa decidiu ainda contrair um empréstimo de 1.000 taéis sobre penhores marítimos para cobrir as despesas e, assim, tentar salvar o seu "mosteiro de recolhidas". ${ }^{82}$

\footnotetext{
$78 \mathrm{AHM} / \mathrm{SCM} / 15$, fl. $47 \mathrm{v}$.

79 AHM/SCM/106, fl. 7

AHM/SCM/106, fl. 10v

AHM/SCM/106, fl. 25.

82 AHM/SCM/106, fl. 26
} 
No ano seguinte, a situação continuava complicada, e a Misericórdia embaraçada em dívidas preocupantes. Em reunião da Mesa de 14 de abril de 1735, decidiu-se mesmo empenhar a prata da igreja da Santa Casa para ser investida em penhores da terra, procurando-se as verbas suficientes para custear o recolhimento em que

[...] se acham as recolhidas que estão no mosteiro desta Santa Casa há mais de três meses sem lhes dar a sua porção de dinheiro e só se lhes tem dado algum arroz para de todo não perecerem e ainda este fiado por não haver dinheiro para pagar o custo dele por não quererem os Reverendos Padres da Companhia de Jesus contribuirem com os 200 taéis anuais que depois de ser erecto o dito recolhimento costumavam dar sempre em cada um ano. ${ }^{83}$

Por fim, em 1737, a Mesa decidiu encerrar o recolhimento e mandar as restantes onze recolhidas "regressar a casa dos parentes por não ter a Misericórdia dinheiro". ${ }^{84}$

A reconstrução do recolhimento da Misericórdia, quarenta anos mais tarde, é resultado, duplamente, de vários legados pios e da urgência em acudir à desesperada situação de profunda pobreza e até marginalidade de muitas órfãs e viúvas cristãs. Os mais importantes legados foram recebidos pela irmandade, significativamente, a partir da fortuna reunida pelo bispo D. Alexandre da Silva Pedrosa Guimarães. ${ }^{85}$ Assim, a 30 de outubro de 1777, o bispo entregou à Misericórdia 595,360 taéis acrescidos de mais 150, a 11 de novembro, os quais renderiam a "risco de mar", até 1787, a soma impressionante de 1836,114 de lucros que, acrescidos ao capital, totalizaram 2581,474 taéis. ${ }^{86}$ No ano seguinte,

\footnotetext{
33 AHM/SCM/106, fl. 29.

84 AHM/SCM/106, fl. 72

85 D. Alexandre da Silva Pedrosa Guimarães nasceu na Bahia, a 21 de julho de 1727, falecendo em Lisboa, em 1799. Foi bispo de Macau entre 1772 e 1789 e governador interino entre 1777 e 1778. Admirador do Marquês de Pombal, foi erudito de relevo e defensor acérrimo do Padroado Português no Oriente. Maria Antónia Espadinha e Leonor de Seabra (coords.), Missionação e missionários na história de Macau (Macau: Universidade de Macau, 2005), pp. 177-81.

${ }^{86} \mathrm{AHM} / \mathrm{SCM} / 304$, fl. 19. Parte importante do dinheiro acumulado nesse período pelo bispado macaense tinha vindo directamente dos cofres dos jesuítas expulsos do território. Em 1767, o bispo de Macau informava oficialmente o Papado possuir 13.000 escudos romanos (scudi romani) que, oriundos do tesouro financeiro do colégio, convento e procuraturas da Companhia de Jesus em Macau, não incluíam os bens imóveis e alfaias (Archivum Secretum Vaticanum, Relationes, 558, fl. 3).
} 
ainda durante o seu governo interino do território, o bispo legou mais 200 taéis de prata para a edificação do recolhimento da Santa Casa que, até 1787 , acumulou ganhos de 441,905 taéis. ${ }^{87}$

O exemplo do bispo foi seguido por vários comerciantes importantes, na sociedade e economia de Macau. Falecido a 3 de fevereiro de 1781, o mercador António José da Costa deixava à Mesa da Misericórdia 2.000 patacas a "riscos do mar" para se verterem os seus lucros para as "recolhidas". ${ }^{88}$ Desaparecido no início de 1787, Domingos Marques estipulava, no seu testamento, uma esmola de 400 patacas a "riscos do mar", "até fazer 1.000", que deveriam ser investidos pela irmandade "para ajuda do sustento das recolhidas no recolhimento de novo instituído". ${ }^{89}$ Algumas das verbas, porém, tiveram de ser imediatamente aplicadas no pagamento das amas privadas que cuidavam dos "órfãos que se acharem na roda, enquanto não se descobrirem pessoas suficientes para os criarem". ${ }^{90}$

Em 1783, o renovado projecto de recolhimento da Misericórdia ainda não estava a funcionar. Reunida a 27 de dezembro, a Mesa da vereação do Leal Senado escrevia à rainha de Portugal, D. Maria I, destacando

[...] a grande miséria e desamparo em que se acham muitas filhas de moradores desta cidade, e muitas órfãs e várias mulheres destituídas de todo o socorro por causa dos frequentes e repetidos naufrágios que sucedem nos navios em que carregam quase todos os habitantes deste domínio, [...]

exemplificando com as desastrosas perdas do navio para Timor, de 1781 para 1782, reunindo "grande parte dos habitantes, mas também muitos e avultados cabedais". Por isso, "para se evitarem infinitos pecados", pediam os senadores à rainha que autorizasse e apoiasse a fundação de "um recolhimento para as meninas órfãs desamparadas", a criar pela Misericórdia e Leal Senado, para o que pediam os antigos edifícios dos expulsos padres jesuítas. ${ }^{91}$ A rainha haveria de conceder ao Leal Sena-

\footnotetext{
AHM/SCM/304, fl. 19v.

AHM/SCM/304, fl. 17

AHM/SCM/304, fl. 19v.

AHM/SCM/99, fl. 159v.

AHM/LS/39, fls. 25-25v
} 
do e à Misericórdia os espaços do antigo seminário de S. José, assim nascendo, desde 1783, uma nova experiência de recolhimento, em que a educação da orfandade feminina começou a mobilizar os primeiros casos de formação pelo trabalho. ${ }^{92}$

\section{Considerações finais}

Pelo que ficou exposto, verificamos a complexidade que o tema apresenta quando inserido no que a historiografia designa de Império Português, pois a escravatura/subalternidade social feminina não apresenta uma única experiência. Na região em estudo, cruzam-se realidades que comprometem a liberdade individual e se manifestam no quotidiano de forma distinta e nem sempre clara.

Muitos dos conceitos que, aqui, apresentamos apenas se aplicam à região em estudo, como é o caso de nhins, nhons e nhonhonhas, referentes à mistura biológica e cultural que se desenvolveu. Outros transmigraram de Portugal para a região, embora possam assumir algumas variantes, e relacionam-se com uma maior ligação ao elemento europeu ou de forte influência europeia, tais como afilhadas e donzelas ou meninas e moças. A condição (teoricamente proibida) de escravas levou à criação de uma nova categoria na estrutura familiar dos portugueses de Macau, a de criações ou crioulas - as quais não são nomeadas de escravas, mas cuja sobrevivência dependia dessas famílias locais que as acolhiam e não dispunham de liberdade de movimentação — assim como as bichas.

Atendendo a que os relacionamentos não se saldavam por um contacto estável, e nem sempre os europeus eram tidos em estima pelos locais, sobretudo em vista das diferenças culturais, muitos soldados, comerciantes, agentes políticos, entre outros, ainda nas décadas finais no século XVI, ligaram-se a grupos femininos subalternos asiáticos por meio do rapto, da compra, da negociação e do resgate escravista. Desde a década de 1590, diversas mulheres conseguidas e resgatadas em distintos lugares dos mares do Sul da China e do Sudeste Asiático, crianças e jovens chinesas continentais, eram compradas ou raptadas em acções

92 AHM/LS/39, fl. 40.

130 Afro-Ásia, 49 (2014), 105-133 
comerciais e marítimas, casando-se muitas delas com portugueses ou ficando suas serviçais ou entrando no mercado sexual. Recrutavam-se crianças e jovens chinesas tanto entre as camadas mais pobres da população, como entre as situações de orfandade da terra. Tal situação suscitou medos e escândalos assim como críticas partidas da Igreja e ordens religiosas missionárias, sobretudo pela enorme extensão do comércio da escravatura (lembre-se que, teoricamente, nem sempre se verificava) feminina impulsionado a partir do porto de Macau.

Como o infanticídio feminino era um procedimento vigente na China, muitos chineses, pressionados pela miséria, em vez de matarem as suas filhas, vendiam-nas aos portugueses. Outros roubavam-nas ou compravam-nas aos seus conterrâneos para as revenderem em Macau. O comércio de crianças roubadas ou revendidas parece ter sido o meio mais usado para aquisição de muitsai, porque os chineses, na sua maioria, temiam represálias dos seus antepassados falecidos, no caso de os seus descendentes mudarem de religião, adoptando a dos bárbaros, uma vez que as crianças lhes fossem vendidas directamente. Surgiram, assim, muitos chineses sem escrúpulos a praticarem esse tráfego com os portugueses de Macau, que, com ele, auferiam grandes lucros.

$\mathrm{Se}$, na realidade, as mulheres europeias não seguiam em número o elemento masculino, não impedia que houvesse um elevado número de mulheres não europeias na sociedade macaense, o que se devia, em parte, à já dita existência de escravas chinesas, ou outras situações de posse, e timorenses que, embora libertas a partir de 1758, permaneceram na cidade, assim como aos frequentes naufrágios, que deixavam muitas mulheres viúvas e crianças ou jovens órfãs de pai. Portanto, muitas dessas mulheres acabavam na prostituição, na cidade.

Uma outra prática corrente e que ajudou em grande escala para o excesso de mulheres deveu-se ao abandono, nos hospitais de enjeitadas, de crianças de sexo feminino chinesas pelas mães, normalmente, não desejadas. Para suavizar o sofrimento e a morte de tais crianças, refira-se a conveniência na sua educação católica, a Santa Casa da Misericórdia tendo assumido um papel social de relevo, mas nem sempre conseguindo evitar que caíssem numa situação de miséria e, normalmente, na prostituição, situação que poderia ser extensiva à mulher europeia. Somente 
a maioria das mulheres europeias e/ou as filhas da terra alcançavam usufruir de um dote que lhes possibilitasse arranjar marido, o que não equivale a uma valorização social.

Portanto, a escravatura feminina em Macau não é sinónimo, apenas, de negra ou de que o elemento negro tenha de estar presente. A partir do século XVIII, a cidade, em determinadas épocas, encontrava-se decaída e, gradualmente, passou a viver das viagens a Timor e a alguns portos da Índia, da Insulíndia e da Indochina, muito longe dos anos de riqueza que decaíram com o fim do século XVII. Às escravas vindas da China juntou-se um elevado número de escravas vindas de Timor, atingindo, nos séculos XVIII e XIX, números elevados, causando grande escândalo mesmo junto da coroa portuguesa. Entretanto, somente pela lei de 23 de fevereiro de 1869 se extinguiu, oficialmente, a escravatura em todos os domínios portugueses.

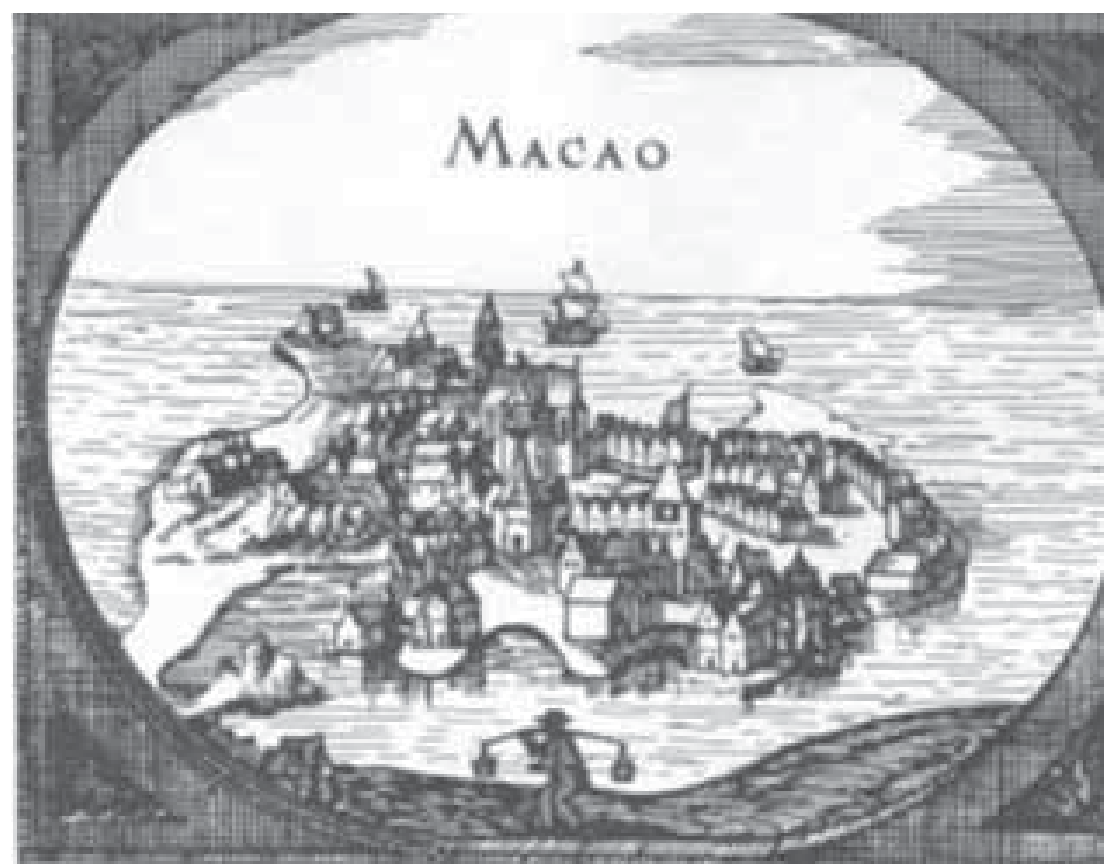

Macau no século XVI 
Texto recebido em 18 de fevereiro de 2013 e aprovado em 15 de julho de 2013

\title{
Resumo
}

Nas últimas décadas, o interesse pela história de Macau tem crescido, mas as análises têm privilegiado a história política, institucional e diplomática. É, porém, nosso objetivo estudar matérias menos usuais: movimentos populacionais e mobilidade social; condição social da mulher e subalternidade feminina. Não nos interessa, apenas, conhecer a ligação de Macau ao reino de Portugal, mas a sua conexão no contexto colonial português e asiático. Assim, analisam-se o elemento luso-asiático da população e os elementos étnicos que contribuíram para a constituição de uma sociedade multicultural.

Palavras-chave: Macau - Oriente - mulher - escrava - mestiçagens

\begin{abstract}
In the last decades, interest in the history of Macau has grown but research into it has favored its political, institutional and diplomatic history. For that reason, it is our objective to study less common topics: populational migrations and social mobility; the woman's social condition and feminine subjugation. We are not only interested in learning their connection regarding Macau to the kingdom of Portugal, but also their connection in the Portuguese and Asian colonial contexts. Thus, the Luso-Asian element of the population and the ethnic elements which contributed to the establishment of a mixed society are analyzed.
\end{abstract}

Keywords: Macau - Orient - woman - slave - mixed ethnicities 